\title{
Utilizing whey protein isolate and polysaccharide complexes to stabilize aerated dairy gels
}

\author{
Emily O'Chiu* $†$ and Bongkosh Vardhanabhuti* ${ }^{* 1}$ \\ *Food Science Program, Division of Food Systems and Bioengineering, University of Missouri, Columbia 65211 \\ †International Food Products, Fenton, MO 63026
}

\begin{abstract}
Heated soluble complexes of whey protein isolate (WPI) with polysaccharides may be used to modify the properties of aerated dairy gels, which could be formulated into novel-textured high-protein desserts. The objective of this study was to determine the effect of polysaccharide charge density and concentration within a WPI-polysaccharide complex on the physical properties of aerated gels. Three polysaccharides having different degrees of charge density were chosen: low-methoxyl pectin, high-methoxyl type D pectin, and guar gum. Heated complexes were prepared by heating the mixed dispersions ( $8 \%$ protein, 0 to $1 \%$ polysaccharide) at $\mathrm{pH} 7$. To form aerated gels, $2 \%$ glucono$\delta$-lactone was added to the dispersions of skim milk powder and heated complex and foam was generated by whipping with a handheld frother. The foam set into a gel as the glucono- $\delta$-lactone acidified to a final $\mathrm{pH}$ of 4.5. The aerated gels were evaluated for overrun, drainage, gel strength, and viscoelastic properties. Without heated complexes, stable aerated gels could not be formed. Overrun of aerated gel decreased (up to $73 \%$ ) as polysaccharide concentration increased from 0.105 to $0.315 \%$ due to increased viscosity, which limited air incorporation. A negative relationship was found between percent drainage and dispersion viscosity. However, plotting of drainage against dispersion viscosity separated by polysaccharide type revealed that drainage decreased most in samples with highcharge-density, low-methoxyl pectin followed by those with low-charge-density, high-methoxyl type D pectin. Aerated gels with guar gum (no charge) did not show improvement to stability. Rheological results showed no significant difference in gelation time among samples; therefore, stronger interactions between WPI and highcharge-density polysaccharide were likely responsible
\end{abstract}

Received September 26, 2016.

Accepted January 5, 2017.

${ }^{1}$ Corresponding author: vardhanabhutib@missouri.edu for increased stability. Stable dairy aerated gels can be created from WPI-polysaccharide complexes. Highcharge-density polysaccharides, at concentrations that provide adequate viscosity, are needed to achieve stability while also maintaining dispersion overrun capabilities.

Key words: whey protein, polysaccharide, foam, aerated gel

\section{INTRODUCTION}

As a byproduct of cheese manufacturing, whey protein can be an economic and environmental burden when unused. Alternatively, its high biological value protein content and unique properties make it a promising food ingredient (Smithers, 2008). Whey protein is commonly added to dairy foods such as yogurt, ice cream, and cheese to increase total protein content, alter textures, or replace more costly ingredients (Singleton, 1973; Kinsella and Whitehead, 1989; Sodini et al., 2005). Understanding whey protein functional properties that allow it to support different food textures is crucial to expanding its use to new applications in the food industry.

There is an opportunity to expand the use of whey protein in nutritionally focused products. As consumers look for more healthful food choices, they have an interest in foods that are more filling with fewer calories. Putting whey protein into an aerated system can address consumer's desire to lower caloric intake in 2 ways. Proteins as a class are more satiating than carbohydrates or fat, and whey protein may suppress gastrointestinal hormones to further improve satiation (Hall et al., 2003; Veldhorst et al., 2009). Additionally, adding bubbles to snack foods such as chocolate or cheese puffs introduces a novelty factor (Campbell and Mougeot, 1999) and has been shown to decrease energy intake by increasing the total food volume per calorie (Osterholt et al., 2007). Potential benefits of aerated gels could include flavor encapsulation or release (or both), delivery of bioactive molecules, control of satiety, and creation of gastronomic structures (Zúñiga and 
Aguilera, 2008, 2009). Using in vitro gastric conditions, Tomczyńska-Mleko and Mleko (2014) revealed that aerated gels could be used in controlled release of minerals. Although whey protein foaming and gelation properties are well understood, little research has been done on aerated whey protein gels.

Aerating foods has a long history through several methods including fermentation, whipping, gas injection, or frying. Many aerated foods such as soufflés, ice cream, and whipped cream rely on fat molecules to support the aerated network (Campbell and Mougeot, 1999; Allen et al., 2006). In a nutritionally focused product, fat content may be undesirable so additional stabilization mechanisms are needed. The functional properties of whey protein can be exploited to prevent system destabilization such as drainage, coalescence, or disproportionation.

In a foam system, stability can come from increased dispersion viscosity, increased interfacial elasticity, or control of bubble size. The amphiphilic nature of whey protein allows it to interact with both the air and water phase of the foam interface. Native whey proteins are able to adhere quickly to the interface to increase stability during the foaming process. In aerated gels, whey protein concentrate has been shown to produce elastic aerated gel by first forming gels and then whipping to form aerated gels (TomczyńskaMleko, 2010; Tomczyńska-Mleko et al., 2014). Zúñiga et al. (2011) used $\beta$-LG to increase gas volume and decrease air bubble size in aerated gelatin gels. When heated, the whey proteins form aggregates or polymers, resulting in slower interfacial adsorption due to their larger size. However, they are better able to stabilize the foam by increasing the interfacial elasticity which increases resistance to deformation forces (Davis and Foegeding, 2004; Schmitt and Turgeon, 2011). Heated whey protein isolate formed at different $\mathrm{pH}$ and heating conditions produced aerated gels with different microstructural and textural properties (Orrego et al., 2015).

The introduction of polysaccharides (PS) into the foam dispersion can work in conjunction with either native whey protein or whey protein polymers to further stabilize the foam. Polysaccharides increase the dispersion viscosity that contributes to foam stability; however, their electrostatic charge also plays an important role. By interacting with oppositely charged regions on the protein, the PS can modify its function at the interface within a range of $\mathrm{pH}$ (Schmitt and Turgeon, 2011).

Further research on the relationship of whey protein and PS focuses on their properties when co-heated as a complex. Typically in a mixed system with 2 charged polymers such as whey proteins and PS, they will either segregate into a bilayer system, or attract and form insoluble aggregates (de Kruif and Tuinier, 2001). However, when dispersions of native whey protein and PS are heated together at a $\mathrm{pH}$ above the protein isoelectric point, the positive patches of the protein that are exposed during unfolding are able to interact with the negatively charged PS to form a heated soluble complex. A study of whey protein foam properties found that heating the whey protein with $\lambda$-carrageenan led to increased foamability and increased drainage time. These changes are attributed to protein-PS interactions improving elasticity and film viscosity of the foam (Wang et al., 2015).

Whey protein-PS heated soluble complexes have also been applied to acid-induced gelation. When whey proteins in dispersion are subjected to gradually lowering $\mathrm{pH}$, the change in the net electric charge of the aggregates allows them to interact and form a gel network (Alting et al., 2002). The addition of PS to the system can be used to alter gel properties and microstructure (Cavallieri and Cunha, 2009). Several PS chemical properties have an effect on the gel microstructure; charge density has the largest effect, followed by molecular weight and chain stiffness (de Jong and van de Velde, 2007). Recent works have shown that acid-induced gels formed from heated whey proteinPS complexes have improved water-holding capacity (WHC) and gel strength compared with those from whey protein polymers with added PS (Zhang et al., 2014; Zhang and Vardhanabhuti, 2014).

We investigated whether heated whey protein-PS complexes could be applied to stabilize aerated whey protein gels by combining their properties in improving both foam and acid-induced gels. To evaluate the effect of both PS concentration and electrostatic charge on the final foam and gel properties, 2 pectins were chosen for this study. Low-methoxyl pectin (LM12) is manufactured with a high degree of esterification and has a high negative charge. High-methoxyl type D pectin (HM D) has a lower degree of esterification and a lower charge but a similar molecular weight to LM12 $(\sim 160 \mathrm{kDa})$. Guar gum was also included in this study as a control PS with a neutral charge.

The objective of this study was to investigate the effect of heated whey protein-PS complexes on low $\mathrm{pH}$ aerated skim milk gel. Several PS were used in the system to look at the roles charge density and PS concentration play on the stability of the aerated system during the acid-induced gelation process. A greater understanding of how heated complex addition can be used to maintain product stability while manipulating properties such as overrun and yield stress will allow the dairy industry to create successful novel-textured products. 


\section{MATERIALS AND METHODS}

\section{Materials}

Whey protein isolate (WPI) containing 93.4\% protein (wet basis), $0.2 \%$ lactose, and $1.9 \%$ minerals was donated by Davisco Foods Intl. (Le Sueur, MN). Skim milk powder (SMP) containing $35 \%$ protein was obtained from a bulk manufacturer. Polysaccharides consisted of LM12 and HM D (CP Kelco, Atlanta, GA), and guar gum (TIC Gums, Belcamp, MD). Acidulation was achieved with either glucono- $\delta$-lactone (GDL) provided by Sigma-Aldrich Corp. (St. Louis, MO) or yogurt cultures containing Streptococcus thermophilus and Lactobacillus bulgaricus provided by DuPont Danisco (Madison, WI). All other chemicals were of analytical grade.

\section{Stock Dispersion Preparation}

The WPI stock dispersion (15\% protein wt/wt) was formed by dissolving protein powder in deionized (DI) water and slowly stirring at room temperature for $\geq 4$ $\mathrm{h}$ for complete hydration. The SMP stock dispersion ( $23.5 \%$ solids, $8 \%$ protein wt/wt) was made in a similar manner. After full hydration, SMP dispersion was held in a $99.9^{\circ} \mathrm{C}$ water bath until it reached $>90^{\circ} \mathrm{C}$ for 5 min. Then, the dispersion was cooled in an ice bath and held at $5^{\circ} \mathrm{C}$ before use. Pectins $(4 \% \mathrm{wt} / \mathrm{wt})$ were stirred on a hotplate to a temperature of $60^{\circ} \mathrm{C}$ for $4 \mathrm{~h}$, then stored at $5^{\circ} \mathrm{C}$ overnight. Guar gum powder was mixed quickly into cold water $(1.33 \% \mathrm{wt} / \mathrm{wt})$ and also stored overnight before use.

\section{Formation of Heated WPI-PS Complexes and Mixing with SMP}

Stock dispersions of WPI and PS were mixed at appropriate amount and their $\mathrm{pH}$ was adjusted to 7.0 using $1 \mathrm{~N} \mathrm{NaOH}$ or $1 \mathrm{~N} \mathrm{HCl}$. The DI water was added such that the final protein concentration was $8 \%$ (wt/ wt) and PS concentration ranged from 0 to $1 \%$ (wt/wt). The mixtures were gently stirred at room temperature for $2 \mathrm{~h}$ before being heated in a temperature-controlled water bath at $85^{\circ} \mathrm{C}$ for $30 \mathrm{~min}$ and cooled in an ice bath. The WPI-PS complexes were then mixed with the heated skim milk in a 60:40 weight ratio. Deionized water was added to all the samples to produce the final protein concentration of $7 \%$. The final $\mathrm{pH}$ of the mixtures was 6.6. The finished samples were stored at $5^{\circ} \mathrm{C}$ overnight before testing for complete interaction between protein and PS.

\section{Viscosity Measurement}

Viscosity measurement was conducted on PS as well as mixed systems of SMP and heated WPI-PS complex dispersions. Polysaccharide dispersions were prepared from the stock dispersions, diluted with DI water and $\mathrm{pH}$ adjusted to 7.0. Viscosity was measured on a Kinexus Pro rheometer (Malvern Instruments Ltd., Worcestershire, UK) using a 65-mm diameter lower plate and 40-mm diameter $4^{\circ}$ cone upper geometry with a $0.15-\mathrm{mm}$ gap. Shear rate was increased from 0.1 to $100 \mathrm{~s}^{-1}$ at $25^{\circ} \mathrm{C}$. The time employed in the measurement was $30 \mathrm{~min}$.

\section{Acid-Induced Gelation}

The GDL was added to the treatments at $2 \%$ (wt/ wt, GDL/total) for all samples except the skim milk control, which required $3.5 \%$ (wt/wt) to reach the same $\mathrm{pH}$ of $4.5 \pm 0.1$ after $24 \mathrm{~h}$ of storage at $5^{\circ} \mathrm{C}$. The mixtures were gently stirred for $30 \mathrm{~s}$ and then three $1.5-\mathrm{mL}$ aliquots were transferred to microcentrifuge tubes for WHC measurement. Samples were covered with parafilm and left overnight at $4^{\circ} \mathrm{C}$. All testing was completed within $24 \pm 1 \mathrm{~h}$ of GDL addition.

\section{Gel Texture Analysis}

Gel samples were removed from the fridge and allowed to equilibrate to room temperature for $2 \mathrm{~h}$ before testing. The cylindrical gel samples had a diameter of $40 \mathrm{~mm}$ and height of $35 \mathrm{~mm}$. A TA-HDi Texture Analyzer (Texture Technologies Corp., Scarsdale, NY) equipped with a $5-\mathrm{kg}$ load cell operated at a test speed of $10 \mathrm{~mm} / \mathrm{s}$ measured force in compression with a 13-mm-diameter stainless-steel probe. The penetration distance was fixed to $10 \%$ of the original gel thickness $(30 \mathrm{~mm})$ and was held for $300 \mathrm{~s}$. The peak force for each sample was recorded.

\section{WHC}

Gel samples (1.5 g) in centrifuge tubes were removed from the refrigerator and allowed to equilibrate to room temperature for $2 \mathrm{~h}$ before testing. Gelled samples were placed in a micro-centrifuge operating at 10,000 rpm $(9,037 \times g)$ for $10 \mathrm{~min}$ at room temperature. The free liquid was removed from the top of each sample by micropipette and weighed in milligrams. The measurements were completed in triplicate. The percent WHC was calculated from the recorded weight of free liquid with the equation below: 


$$
\% \mathrm{WHC}=\frac{(1,500-\text { recorded } \mathrm{wt})}{1,500} \times 100 \text {. }
$$

\section{Formation of Aerated Gel}

For consistent foaming conditions, foam samples were created by placing $40 \mathrm{~g}$ of each test treatment into a $250-\mathrm{mL}$ beaker. The GDL was added at $2 \%$ (wt/ wt, GDL/total) for all samples except the skim milk control, which required $3.5 \%$ (wt/wt) as previously described. The samples were stirred quickly for $30 \mathrm{~s}$ to dissolve the crystals. Immediately after GDL addition, the samples were whipped for $2 \mathrm{~min}$ with a handheld Aerolatte frothing wand (Aerolatte Ltd., Radlett, UK) connected to a 3.7-V, 0.35-A power adapter for consistent power supply. The device consists of a whisk rotor with an outer diameter of $22 \mathrm{~mm}$ rotated about a vertical axis at a rotational speed of approximately 12,000 rpm in air. All foam property measurements were taken immediately after aeration.

\section{Drainage}

To measure the degree of liquid drainage from the foam before gelation set in, the aerated dispersion was poured into a $15-\mathrm{mL}$ centrifuge tube until it was level with the top (15.75 mL total volume). The weight of the foam in the tube was recorded. After $15 \mathrm{~min}$, the aerated dispersion had gelled and the volume of liquid that had drained from the foam and collected at the bottom of the tube was recorded. Density of the dispersion was determined by weighing $100 \mathrm{~mL}$ of the sample in a $100-\mathrm{mL}$ measuring cylinder. Percent drainage was calculated using the equation below:

$$
\% \text { drainage }=\frac{\mathrm{mL} \text { of drained liquid } \times \text { density }}{\text { total weight of foam in tube }} \times 100 \text {. }
$$

\section{Overrun}

Immediately after whipping, foam overrun was measured by gently transferring the foam into a pre-weighed $35 \mathrm{~mm}$ diameter $\times 10 \mathrm{~mm}$ Petri dish $(9.62 \mathrm{~mL}$ total volume). The dish was filled to above the rim, then a metal spatula was used to level off the top of the foam for consistent volume before recording the weight. The measurement was completed in triplicate. The percent overrun was calculated using Equation [3]:

$\%$ Overrun $=\frac{(9.62 \times \text { density })-\text { recorded weight }}{\text { recorded weight }} \times 100$.

\section{Viscoelastic Properties}

Further study of small strain deformation of the aerated gels was conducted on samples containing $0.315 \%$ PS. This concentration was chosen because it was the first to form a stable aerated gel (for LM12). Samples with lower PS concentrations were excluded because the liquid drainage from the foam created a nonhomogeneous structure.

\section{Viscoelastic Properties of Aerated Gels}

Immediately after whipping, foams were gently loaded into the Kinexus Pro Rheometer with a plate and plate geometry (50 mm upper plate) with a $1 \mathrm{~mm}$ loading gap. The excess foams were gently removed and the solvent trap was used to prevent sample drying. The foam was left to stabilize for $2 \mathrm{~min}$ before testing. The development of elastic modulus $\left(\mathbf{G}^{\prime}\right)$ was monitored in the predetermined linear region ( $0.5 \%$ strain) at a constant frequency of $1 \mathrm{~Hz}$ at $25^{\circ} \mathrm{C}$ for $6 \mathrm{~h}$. Sample gelation time was determined by recording the point where the change in $\mathrm{G}^{\prime}$ during gel formation is discernable from background noise as defined by Horne (1999). The $\mathrm{G}^{\prime}$ at $6 \mathrm{~h}$ after GDL addition was chosen to represent the final $\mathrm{G}^{\prime}$.

\section{Yield Stress}

After whipping, foam was gently loaded on the Kinexus Pro Rheometer using $40 \mathrm{~mm}$ serrated upper and lower plates with a $1 \mathrm{~mm}$ gap. The excess foams were gently removed and the solvent trap was used to prevent sample drying. Aerated gel was allowed to form in situ for $2 \mathrm{~h}$. A single shear rate of 0.01 was applied for $10 \mathrm{~min}$. Yield stress was defined as the peak recorded shear stress $(\sigma)$.

\section{Lactic Acid Bacteria Gelation}

Yogurt starter cultures containing Streptococcus thermophilus and Lactobacillus bulgaricus were added at $0.01 \%$ concentration to the sample dispersion as recommended by the manufacturer. After $30 \mathrm{~min}$ of gentle stirring at room temperature, the samples were foamed, poured into $15-\mathrm{mL}$ centrifuge tubes, and incubated at $42^{\circ} \mathrm{C}$ for $6 \mathrm{~h}$. After incubation, drainage measurements were conducted in the same manner as for the GDL samples. The sample $\mathrm{pH}$ was also recorded.

\section{Statistical Analysis}

Statistical analysis was completed with SAS version 9.3 (SAS Institute Inc., Cary, NC). All values are means 
\pm standard deviation. Statistical differences were analyzed using PROC GLM for ANOVA followed by the Tukey-Kramer test and for regression analysis. $P$-values $<0.05$ were considered statistically significant. All statistical analysis was done on at least 2 replications.

\section{RESULTS AND DISCUSSION}

The formation of the aerated gels in this study was done with a handheld frother, a relatively new method that was also found in a previous study on lactoglobulin and casein foam coarsening (Blijdenstein et al., 2010). Preliminary tests of overrun and drainage on SMP with heated WPI-PS complexes showed that the test was repeatable (e.g., $\mathrm{CV}<10 \%$ ) if both the time between dispersion mixing and testing and the time between GDL addition and testing were controlled (results not shown). All aerated gels contained 7\% (wt/wt) protein. Samples with mixed SMP and heated WPI-PS complexes contained 40:60 SMP to complexes ratio.

\section{Aerated Gel Overrun}

Overrun of aerated gels ranged from 30.6 to $120 \%$ for SMP gels with heated WPI-LM12 pectin complexes

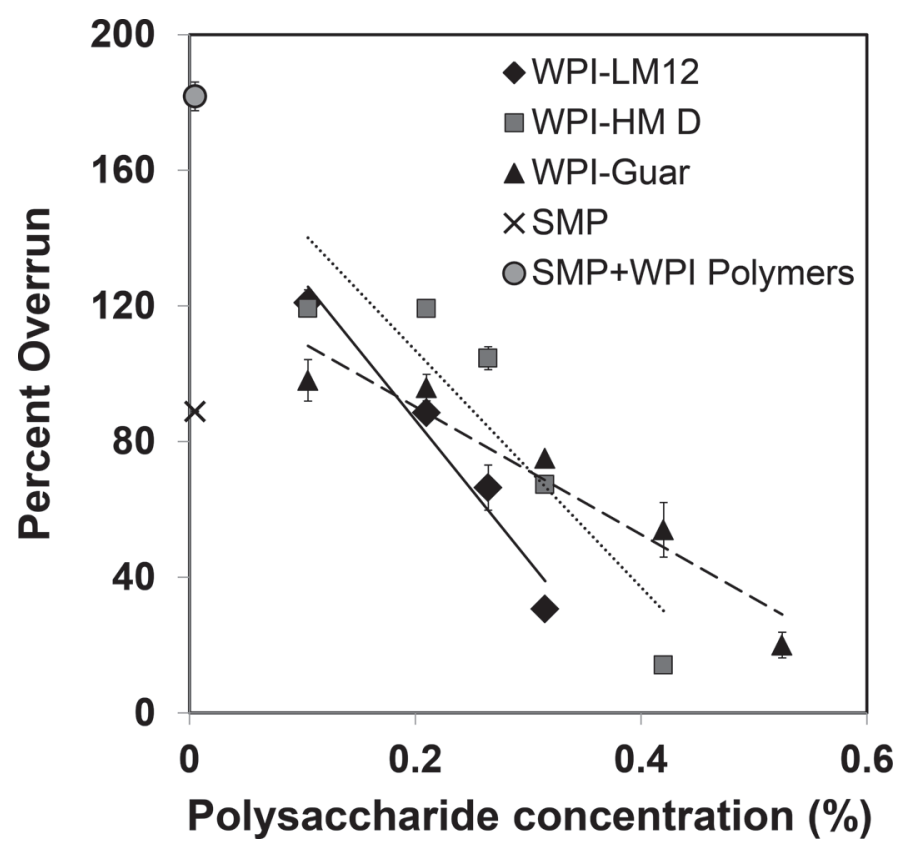

Figure 1. Percent overrun of the aerated gels for all concentrations of whey protein isolate (WPI)-low-methoxyl (LM12) pectin, WPI-high methoxyl (HM D) pectin, WPI-guar gum (WPI-Guar), and controls. Samples organized by type with trendlines: solid line: WPI-LM12 pectin; dashed line: WPI-HM D pectin; dotted line: WPI-Guar. SMP = skim milk protein. Error bars represent SD.
(WPI-LM12 pectin), 14.1 to $119 \%$ for heated WPI-HM D complexes (WPI-HM D pectin), and 20.0 to $98 \%$ for heated WPI-Guar gum complexes (WPI-Guar). Both increasing PS concentration and high shear viscosity were found to be strong predictors of foam overrun $(P$ $<0.0001)$. As expected, overrun decreased significantly as PS concentration and dispersion viscosity increased (Figures 1 and 2). Several studies have reported the negative correlation between overrun of protein foams and the viscosity of pre-foam dispersions at the shear rate corresponding to whipping shear rate (Campbell and Mougeot, 1999; Mott et al., 1999; Pintor and Totosaus, 2012). Because the exact shear rate of the Aerolatte frother is not known, we analyzed the relationship between the overrun and the viscosity at shear rates of 50,80 , and $100 \mathrm{~s}^{-1}$. The same relationships were found at all 3 shear rates. Viscosity values at a shear rate of $100 \mathrm{~s}^{-1}$ are reported in Table 1 and Figure 2.

It is expected that dispersions with higher viscosity would have lower overrun as the viscosity limits air incorporation during frothing. In the same vein, it is expected that increasing PS concentration will decrease overrun due to increased viscosity. The control sample containing heated SMP and WPI polymers with no PS had by far the highest overrun $(178 \pm 4.2 \%)$; however, that sample is unsuitable for an aerated gel product due to its poor stability. Similarly, at $0.315 \%$ PS, the

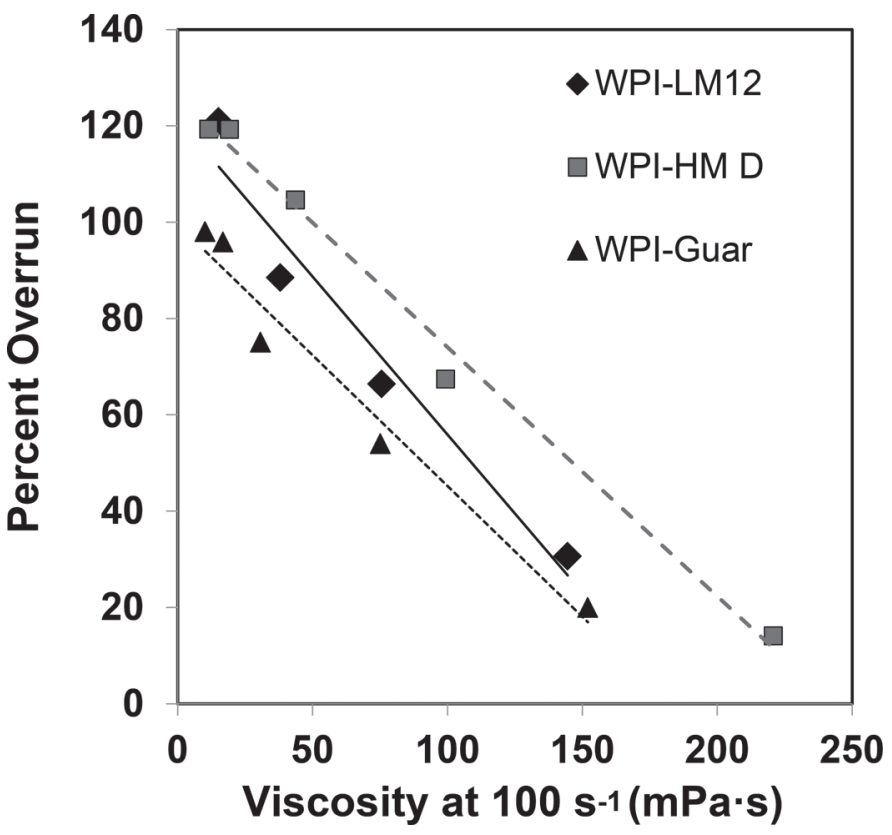

Figure 2. Percent overrun versus high shear viscosity of samples organized by type with trendlines [solid line: whey protein isolate (WPI)-low-methoxyl (LM12) pectin; dashed line: WPI-high-methoxyl (HM D) pectin; dotted line: WPI-guar gum (Guar)]. 
overrun of complex samples with guar gum $(75.1 \%)$ was higher than that with HM D pectin $(67.4 \%)$, which was higher than that with LM12 pectin $(30.6 \%)$; however, only LM12 pectin gave stable aerated gel. This demonstrates that when comparing PS it is important to compare the overruns of the stable aerated gels with no drainage. When only stable samples were compared, the complex containing the higher charge density PS (WPI-LM12) was able to stabilize at lower concentration and thus lower viscosity and higher overrun (30.6 $\pm 2.9 \%)$ than the low charge WPI-HM D $(14.1 \pm 1.2 \%)$. This indicates that high-charge-density PS will allow formulations with a wider range of possible overruns.

\section{Stability of Aerated Gels}

Drainage, an indicator of foam stability, is generally measured as the time it takes for half of the foam by weight to drain from its container or for half of the height of the foam to collapse within a column (Lau and Dickinson, 2005). With aerated gels, the loss of foam stability can be seen as the volume of liquid that drains from the foam before gelation occurs (Tomczynska-Mleko, 2013a,b). In samples with no drainage, air bubbles can be seen spread evenly throughout the gel network. When drainage occurs, a 2-phase system forms with the air bubbles creaming at the top of the container and a distinct gel layer with no air at the bottom. Collapsing of the foam resulting in a decrease in volume was only seen in the least stable SMP control samples. Here, stability is expressed as percent drainage by weight to control for the change in total aerated gel weight at the same volume with different overruns.

Without heated complexes, SMP alone could not form stable aerated gels; drainage began immediately after aeration. Stable aerated gel was also not achieved when heated whey protein (WPI-polymers) was used. It should be noted that addition of PS to SMP (without WPI) is not advised due to depletion interactions that typically occur between casein and PS and cause phase separation (de Kruif, 1999). Replacing $60 \%$ of the SMP with heated complexes resulted in decreased drainage of aerated gels. Stability was significantly affected by PS concentration $(P<0.0001)$ and the type of PS $(P$ $<0.0001)$. Increasing PS concentration resulted in a decrease in percent drainage across all PS except guar gum at $0.525 \%$ (Figure 3). Complete stability (no drainage) was achieved at $\geq 0.315$ and $\geq 0.415 \%$ of WPI-LM12 and WPI-HM D, respectively. Percent drainage of aerated gels formed with heated WPI-Guar could only be reduced to $38 \%$. The percent drainage for WPI-LM12 ranged from $0 \pm 0$ to $65.9 \pm 1.3$, from $0 \pm$ 0 to $70.4 \pm 0.08$ for WPI-HM D, and from $38.1 \pm 2.1$ to $75.6 \pm 1.32$ for WPI-Guar (Figure 3 and Table 1 ).

Because increased low shear viscosity is known to increase foam stability, the relationship between viscosity at $8 \mathrm{~s}^{-1}$ shear and drainage was also analyzed. No relationship was found between the viscosity of just the PS being added to the system, and final sample stability (data not shown). When the viscosity of the sample dispersions is plotted against sample percent drainage a negative relationship is seen that is significantly different between the 3 PS $(P<0.0005)$. The improvement in drainage for the same increase in viscosity is different based on the charge density of the PS within the complex. The WPI-LM12 sample percent drainage decreases at a slope of -21.4 . The lower charge WPIHM D samples have a slope of -17.4 . No relationship was found for guar gum between drainage and viscosity (Figure 4).

Table 1. Effect of viscosity on drainage and overrun of aerated gels containing different whey protein isolate (WPI)-polysaccharide complexes ${ }^{1}$

\begin{tabular}{|c|c|c|c|c|c|}
\hline Type & $\% \mathrm{PS}$ & $\begin{array}{c}\text { Viscosity at } 8 \mathrm{~s}^{-1} \\
(\mathrm{mPa} \cdot \mathrm{s})\end{array}$ & $\begin{array}{c}\text { Viscosity at } 100 \mathrm{~s}^{-1} \\
(\mathrm{mPa} \cdot \mathrm{s})\end{array}$ & Percent overrun & Percent drainage \\
\hline WPI-LM12 & 0.105 & $21.6 \pm 0.1^{\mathrm{a}}$ & $15.2 \pm 0.1^{\mathrm{ab}}$ & $120 \pm 3^{\mathrm{i}}$ & $65.9 \pm 1.3^{\text {ef }}$ \\
\hline WPI-HM D & 0.105 & $12.5 \pm 0.2^{\mathrm{a}}$ & $11.6 \pm 0.2^{\mathrm{ab}}$ & $119 \pm 2^{\mathrm{i}}$ & $70.4 \pm 0.1^{\text {ef }}$ \\
\hline WPI-LM12 & 0.210 & $63.1 \pm 0.8^{\mathrm{abc}}$ & $38.1 \pm 0.2^{\mathrm{bc}}$ & $88.5 \pm 2.1^{\mathrm{g}}$ & $44.3 \pm 2.4^{\mathrm{cd}}$ \\
\hline WPI-HM D & 0.210 & $23.0 \pm 0.9^{\mathrm{a}}$ & $19.3 \pm 0.8^{\mathrm{abc}}$ & $119 \pm 0^{\mathrm{i}}$ & $58.9 \pm 0.4^{\text {de }}$ \\
\hline WPI-Guar & 0.210 & $16.9 \pm 0.0^{\mathrm{a}}$ & $16.8 \pm 0.4^{\mathrm{abc}}$ & $95.9 \pm 3.9^{\mathrm{gh}}$ & $56.2 \pm 0.8^{\mathrm{de}}$ \\
\hline WPI-LM12 & 0.315 & $539 \pm 78^{\mathrm{f}}$ & $144 \pm 3^{\mathrm{e}}$ & $30.6 \pm 2.9^{c}$ & $0 \pm 0^{\mathrm{a}}$ \\
\hline WPI-HM D & 0.315 & $415 \pm 32^{\mathrm{e}}$ & $99.4 \pm 2.5^{\mathrm{d}}$ & $67.4 \pm 0.5^{\mathrm{e}}$ & $14.0 \pm 4.4^{\mathrm{b}}$ \\
\hline WPI-Guar & 0.315 & $26.4 \pm 3.2^{\mathrm{ab}}$ & $30.7 \pm 1.4^{\mathrm{abc}}$ & $75.1 \pm 0.8^{\mathrm{f}}$ & $47.4 \pm 8.1^{\mathrm{cd}}$ \\
\hline WPI-HM D & 0.420 & $535 \pm 39^{\mathrm{f}}$ & $220 \pm 7^{\mathrm{f}}$ & $14.1 \pm 1.2^{\mathrm{a}}$ & $0 \pm 0^{\mathrm{a}}$ \\
\hline WPI-Guar & 0.420 & $136 \pm 22^{\mathrm{c}}$ & $75.2 \pm 3.1^{\mathrm{d}}$ & $54.0 \pm 8.0^{\mathrm{d}}$ & $38.1 \pm 2.0^{\mathrm{c}}$ \\
\hline WPI-Guar & 0.525 & $305 \pm 5^{\mathrm{d}}$ & $152 \pm 0^{\mathrm{e}}$ & $20.0 \pm 3.8^{\mathrm{b}}$ & $55.0 \pm 0.2^{\mathrm{de}}$ \\
\hline
\end{tabular}

\footnotetext{
${ }^{\mathrm{a}-\mathrm{i}}$ Different superscript letters represent significant differences in the means of the same parameter $(P<0.05)$.

${ }^{1}$ Values are mean \pm SD. PS $=$ polysaccharides; WPI-LM12 = whey protein isolate, low methoxyl pectin; WPI-HM D = whey protein isolate, high-methoxyl type D pectin; WPI-Guar = whey protein isolate, guar gum.
} 
WHC

No difference was present in the WHC for the WPI-pectin samples at any concentration (results not shown). The average measured WHC was $96.7 \pm 0.9 \%$ for all samples excluding the $0.315 \%$ concentration of guar gum, which had $67.3 \pm 1.7 \%$ WHC. The WHC was not measured on samples with PS concentrations higher than $0.315 \%$.

It is expected that all the samples containing WPIpectin and the lower concentrations of WPI-Guar would have similar WHC results. Previous research established that heated WPI-PS complexes have high WHC at these concentrations; differences based on charge density are not seen until higher PS concentrations (Zhang and Vardhanabhuti, 2014). Poor WHC is associated with high drainage as was seen with the $0.315 \%$ WPI-Guar sample with high drainage related phase separation before gelation. Water-holding capacity is also an important indicator of shelf life as it is linked to syneresis defects in gels (Keogh and O'Kennedy, 1998). Samples with high WHC that were stored for $14 \mathrm{~d}$ at $5^{\circ} \mathrm{C}$ did not display any further syneresis in a preliminary shelf life trial (results not shown).

\section{Viscoelastic Properties}

The viscoelastic properties of protein-based gels and foams are affected by acidulation rate and dispersion pH (Allen et al., 2006; Zhang et al., 2014). Among our samples, no significant difference was found for gelation time of the 3 PS types $(P=0.061)$. Additionally the samples all had a pH of $4.49 \pm 0.0524 \mathrm{~h}$ after GDL addition. This indicates that differences found can be attributed to the differing chemical structure of the WPI-PS complexes. The elastic modulus $\left(\mathrm{G}^{\prime}\right)$ is a measure of gel deformation under force and relates to the solid-like properties and mouthfeel of a gel. The equivalent measure for a foam system is yield stress, which indicates the force at which the foam stops acting like a viscoelastic solid and begins to flow. Because an aerated gel may have both gel-like and foam-like qualities, we analyzed which of the measured characteristics had an effect on either $\mathrm{G}^{\prime}$ or yield stress (Table 2).

Significant differences were present in the aerated gel final $\mathrm{G}^{\prime}(P=0.0021)$ by PS type. The WPI-LM12 had the highest $\mathrm{G}^{\prime}$, followed by WPI-Guar and WPI-HM D. Gel strength and gel overrun together are predictive of final $\mathrm{G}^{\prime}(P=0.0011)$ with samples with lower overrun or higher gel strength having higher $\mathrm{G}^{\prime}$. The inclusion of air in a gel has been shown to increase the $\mathrm{G}^{\prime}$ when compared with nonaerated gels (Tomczyńska-Mleko, 2013). In general, complexes made with high-chargedensity PS will have higher gel strength due to the

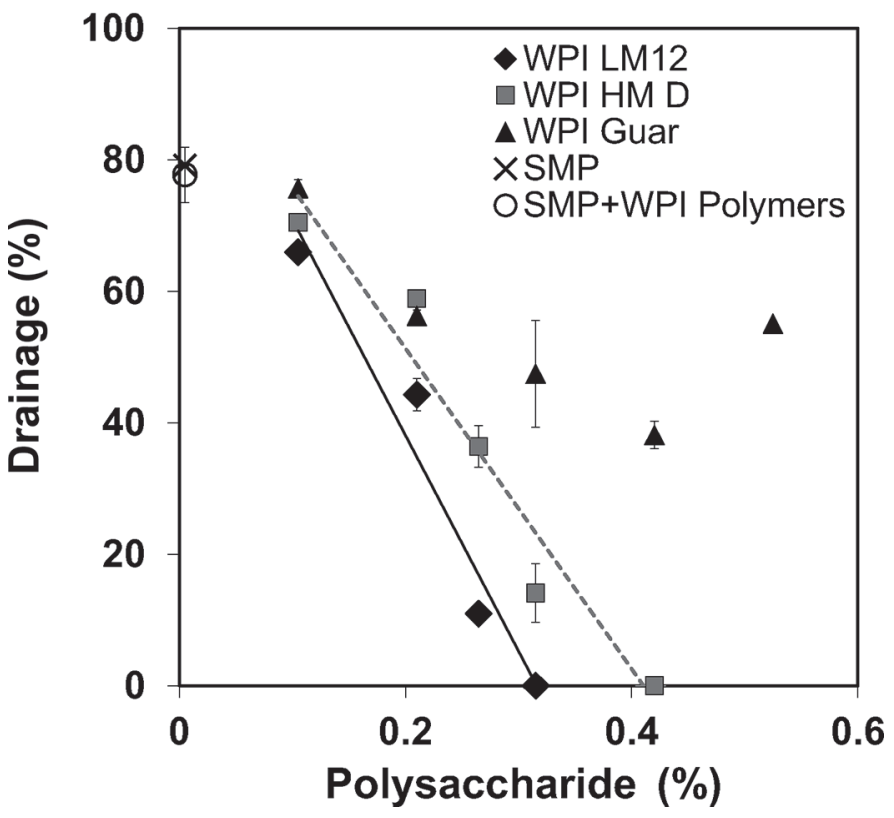

Figure 3. Percent drainage of the aerated gels for all concentrations of whey protein isolate (WPI)-low-methoxyl (LM12) pectin, WPI-high-methoxyl type D (HM D) pectin, WPI-guar gum (WPIGuar), and controls. Samples organized by type with trendlines (solid line: WPI-LM12 pectin; dashed line: WPI-HM D pectin). SMP = skim milk protein. Error bars represent SD.

increased protein-protein interactions in the gel network; these increased protein-protein interactions also contribute to increased $\mathrm{G}^{\prime}$ (Zhang et al., 2014). How-

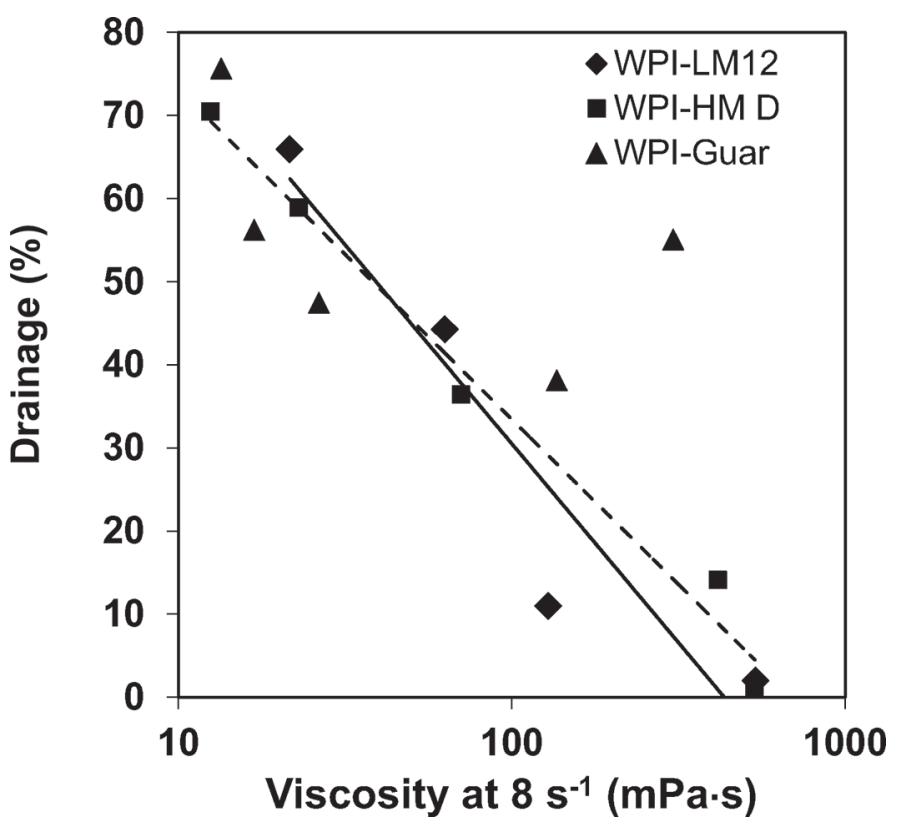

Figure 4. Percent drainage versus low shear viscosity of samples organized by type with trendlines [solid line: whey protein isolate (WPI)-low-methoxyl (LM12) pectin; dashed line: WPI-high-methoxyl type D (HM D) pectin]. Guar = guar gum. 


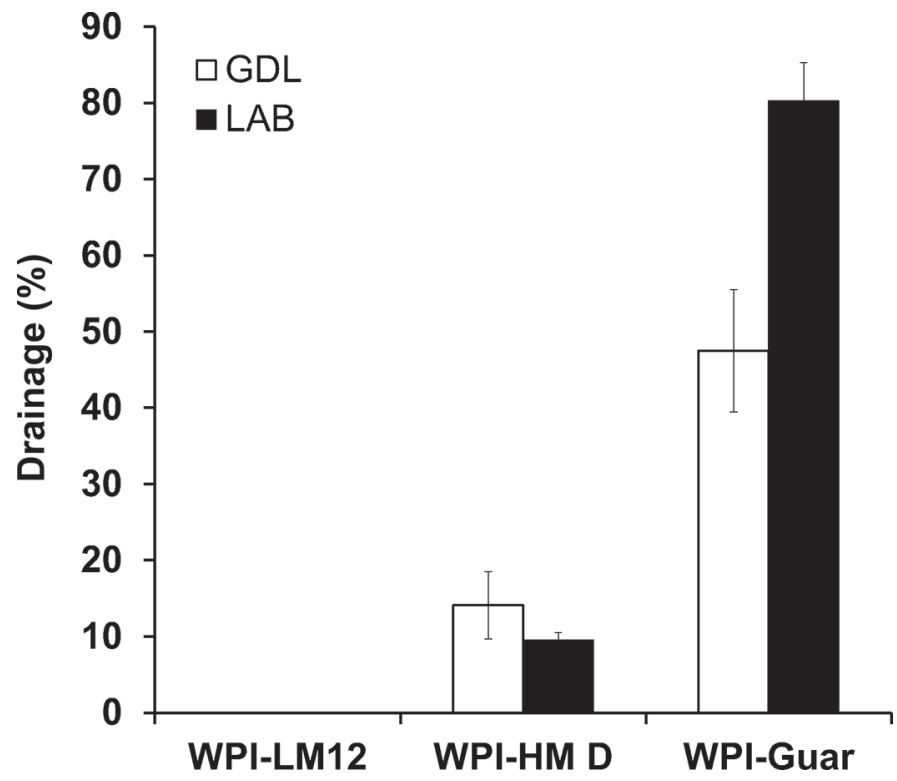

Figure 5. Percent drainage for the aerated gels at polysaccharide concentration $0.315 \%$ with 2 acidulation methods: glucono- $\delta$-lactone (GDL; white) and lactic acid bacteria (LAB; black). WPI-LM12 = whey protein isolate, low-methoxyl pectin; WPI-HM D = whey protein isolate, high-methoxyl type D pectin; WPI-Guar = whey protein isolate, guar gum. Error bars represent SD.

ever, they can also contribute to increase dispersion viscosity before gelation, which, as has been previously discussed, limits overrun. The WPI-Guar complex does not follow this trend as it experiences phase separation, which can artificially inflate gel strength results.

The different PS had significantly different aerated gel yield stress $(P=0.0168)$. Individually, no relationship was present between either gel strength and yield stress $(P=0.3938)$ or overrun and yield stress $(P=0.1959)$. However, when considered together gel strength and overrun are predictive of sample yield stress $(P=0.041)$ with higher gel strength and lower overrun associated with higher yield stress (Table 2). The yield stress was highest for the WPI-LM12 samples. In these, like in the case of $\mathrm{G}^{\prime}$, the increased protein-protein interactions of the complex lead to increased durability of the foam structure. The yield stress values for WPI-Guar were between those of WPI-LM12 and WPI-HM D. This may be due to the lower viscosity and higher overrun of guar gum at the selected concentration.

\section{Lactic Acid Bacteria Gelation}

The primary acidulation agent in this study is GDL; it has consistent results with a fast initial $\mathrm{pH}$ decrease. However, the primary application of dairy aerated gels is for whipped yogurts. Milk fermentation with lactic acid bacteria is a slower process than with GDL. We repeated the drainage study on samples acidulated with lactic acid bacteria to study how stability is affected by acidulation rate.

Drainage results with the 2 acidulation agents were significantly different $(P<0.0001)$. Overall, the lactic acid bacteria samples had higher percent drainage than the GDL samples $(P=0.0076$; Figure 5$)$. The stability of aerated gels acidified with yogurt bacterial cultures followed the same trend of increased stability with higher charged PS. Only the $0.315 \%$ LM12 pectin dispersion had zero drainage. The slower acidulation rate did not affect drainage for HM D, but the guar gum drainage almost doubled. One explanation is that at these concentrations the viscosity of the HM D dispersion is $415.8 \pm 32.8 \mathrm{mPa} \cdot \mathrm{s}$ and for guar gum it is $26.5 \pm 3.2 \mathrm{mPa} \cdot \mathrm{s}$, so the higher viscosity of the HM D sample may have protected it from increased drainage during a longer gelation time.

\section{CONCLUSIONS}

The results of this study confirm that both PS concentration and electrostatic charge density have an effect on the final properties of aerated gels. It is possible to create stable aerated gels with WPI-PS complexes by adjusting the PS type and use level. High-chargedensity PS, at concentrations that provide adequate viscosity, are needed to achieve stability while also maintaining dispersion overrun capabilities. This can be applied to dairy-based gels set by acid or calcium such as yogurt or mousses where aeration can increase their appeal by creating novel textures and reducing calories by volume.

Table 2. Viscoelastic properties of aerated gels at $0.315 \%$ polysaccharide $(\mathrm{PS})^{1}$

\begin{tabular}{|c|c|c|c|c|c|c|c|}
\hline Type & $\%$ PS & $\begin{array}{l}\text { Gelation time } \\
(\mathrm{s})\end{array}$ & $\begin{array}{c}\text { Final G' } \\
(\mathrm{kPa})\end{array}$ & $\begin{array}{l}\text { Yield stress } \\
\quad(\mathrm{Pa})\end{array}$ & $\begin{array}{c}\text { Gel strength } \\
(\mathrm{g})\end{array}$ & $\begin{array}{l}\text { Percent } \\
\text { overrun }\end{array}$ & $\begin{array}{l}\text { Viscosity } \\
(\mathrm{mPa} \cdot \mathrm{s})\end{array}$ \\
\hline WPI-LM12 & 0.315 & $495 \pm 23^{\mathrm{a}}$ & $10.5 \pm 0.3^{\mathrm{b}}$ & $1,550 \pm 14^{\mathrm{b}}$ & $235 \pm 7^{\mathrm{b}}$ & $30.6 \pm 2.8$ & $540 \pm 78$ \\
\hline WPI-HM D & 0.315 & $415 \pm 20^{\mathrm{a}}$ & $7.4 \pm 0.2^{\mathrm{a}}$ & $468 \pm 59^{\mathrm{a}}$ & $203 \pm 11^{\mathrm{a}}$ & $67.4 \pm 0.5$ & $416 \pm 32$ \\
\hline
\end{tabular}

\footnotetext{
${ }^{\mathrm{a}-\mathrm{c}}$ Different superscript letters represent significant differences in the means of the same parameter $(P<0.05)$.

${ }^{1}$ Values are mean $\pm \mathrm{SD} . \mathrm{G}^{\prime}=$ elastic modulus; WPI-LM12 = whey protein isolate, low-methoxyl pectin; WPI-HM D = whey protein isolate, high-methoxyl type D pectin; WPI-Guar = whey protein isolate, guar gum.
} 


\section{ACKNOWLEDGMENTS}

The authors thank Davisco Foods International Inc., CP Kelco, and TIC Gums for providing WPI, pectins, and guar gum, respectively. This work was partially supported by the National Institute of Food and Agriculture, USDA, Hatch Project number 233858. Any findings, conclusions, or recommendations expressed in this publication are those of the authors and do not necessarily reflect the view of the National Institute of Food and Agriculture or the USDA.

\section{REFERENCES}

Allen, K. E., E. Dickinson, and B. Murray. 2006. Acidified sodium caseinate emulsion foams containing liquid fat: A comparison with whipped cream. Lebensm. Wiss. Technol. 39:225-234.

Alting, A. C., H. H. J. de Jongh, R. W. Visschers, and J.-W. F. A. Simons. 2002. Physical and chemical interactions in cold gelation of food proteins. J. Agric. Food Chem. 50:4682-4689.

Blijdenstein, T. B. J., P. W. N. de Groot, and S. D. Stoyanov. 2010. On the link between foam coarsening and surface rheology: Why hydrophobins are so different. Soft Matter 6:1799-1808.

Campbell, G. M., and E. Mougeot. 1999. Creation and characterisation of aerated food products. Trends Food Sci. Technol. 10:283-296.

Cavallieri, L. F., and R. L. Cunha. 2009. Cold-set whey protein gels with addition of polysaccharides. Food Biophys. 4:94-105.

Davis, J. P., and E. A. Foegeding. 2004. Foaming and interfacial properties of polymerized whey protein isolate. J. Food Sci. 69:C404C410.

de Jong, S., and F. van de Velde. 2007. Charge density of polysaccharide controls microstructure and large deformation properties of mixed gels. Food Hydrocoll. 21:1172-1187.

de Kruif, C. G. 1999. Casein micelle interactions. Int. Dairy J. 9:183188.

de Kruif, C. G., and R. Tuinier. 2001. Polysaccharide protein interactions. Food Hydrocoll. 15:555-563.

Hall, W. L., D. J. Millward, S. J. Long, and L. M. Morgan. 2003. Casein and whey exert different effects on plasma amino acid profiles, gastrointestinal hormone secretion and appetite. Br. J. Nutr. 89:239-248.

Horne, D. S. 1999. Formation and structure of acidified milk gels. Int. Dairy J. 9:261-268.

Keogh, M. K., and B. T. O'Kennedy. 1998. Rheology of stirred yogurt as affected by added milk fat, protein and hydrocolloids. J. Food Sci. 63:108-112.

Kinsella, J. E., and D. M. Whitehead. 1989. Proteins in whey: Chemical, physical, and functional properties. Adv. Food Nutr. Res. 33:343-438.

Lau, C. K., and E. Dickinson. 2005. Instability and structural change in an aerated system containing egg albumen and invert sugar. Food Hydrocoll. 19:111-121.

Mott, C. L., N. S. Hettiarachchy, and M. Qi. 1999. Effect of xanthan gum on enhancing the foaming properties of whey protein isolate. J. Am. Oil Chem. Soc. 76:1383-1386.
Orrego, M., E. Troncoso, and R. N. Zúñiga. 2015. Aerated whey protein gels as new food matrices: Effect of thermal treatment over microstructure and textural properties. J. Food Eng. 163:37-44.

Osterholt, K. M., L. S. Roe, and B. J. Rolls. 2007. Incorporation of air into a snack food reduces energy intake. Appetite 48:351-358.

Pintor, A., and A. Totosaus. 2012. Ice cream properties affected by lambda-carrageenan or iota-carrageenan interactions with locust bean gum/carboxymethylcellulose mixtures. Int. Food Res. J. 19:1409-1414.

Schmitt, C., and S. L. Turgeon. 2011. Protein/polysaccharide complexes and coacervates in food systems. Adv. Colloid Interface Sci. 167:63-70.

Singleton, A. D. 1973. Whey usage in dairy products. Pages $52-56$ in Proc. Whey Products Conf., Chicago, IL.

Smithers, G. W. 2008. Whey and whey proteins-From 'gutter-togold'. Int. Dairy J. 18:695-704.

Sodini, I., J. Montella, and P. S. Tong. 2005. Physical properties of yogurt fortified with various commercial whey protein concentrates. J. Sci. Food Agric. 85:853-859.

Tomczyńska-Mleko, M. 2010. Aerated gels obtained from whey protein concentrate. Milchwissenschaft 65:180-183.

Tomczyńska-Mleko, M. 2013a. Structure and rheology of aerated whey protein isolate gels obtained at different pH. J. Food Nutr. Res. 52:61-70.

Tomczyńska-Mleko, M. 2013b. Structure and stability of ion induced whey protein aerated gels. Czech J. Food Sci. 31:211-216.

Tomczyńska-Mleko, M., W. Gustaw, T. Piersiak, and S. Mleko. 2014 Whey protein aerated gels as a new product obtained using ambient temperature magnesium and iron(II) induced gelation. Acta Aliment. 43:465-472.

Tomczyńska-Mleko, M., and S. Mleko. 2014. Whey protein aerated gels as matrices for controlled mineral release in simulated gastric conditions. Food Res. Int. 62:91-97.

Veldhorst, M. A. B., A. G. Nieuwenhuizen, A. Hochstenbach-Waelen, A. J. A. H. van Vught, K. R. Westerterp, M. P. K. J. Engelen, R.J. M. Brummer, N. E. P. Deutz, and M. S. Westerterp-Plantenga. 2009. Dose-dependent satiating effect of whey relative to casein or soy. Physiol. Behav. 96:675-682.

Wang, Z., S. Zhang, and B. Vardhanabhuti. 2015. Foaming properties of whey protein isolate and $\lambda$-carrageenan mixed systems. J. Food Sci. 80:N1893-N1902.

Zhang, S., F.-H. Hsieh, and B. Vardhanabhuti. 2014. Acid-induced gelation properties of heated whey protein-pectin soluble complex (Part I): Effect of initial pH. Food Hydrocoll. 36:76-84.

Zhang, S., and B. Vardhanabhuti. 2014. Acid-induced gelation properties of heated whey protein-pectin soluble complex (Part II): Effect of charge density of pectin. Food Hydrocoll. 39:95-103.

Zúñiga, R. N., and J. M. Aguilera. 2008. Aerated food gels: Fabrication and potential applications. Trends Food Sci. Technol. 19:176-187.

Zúñiga, R. N., and J. M. Aguilera. 2009. Structure-fracture relationships in gas-filled gelatin gels. Food Hydrocoll. 23:1351-1357.

Zúñiga, R. N., U. Kulozik, and J. M. Aguilera. 2011. Ultrasonic generation of aerated gelatin gels stabilized by whey protein $\beta$-lactoglobulin. Food Hydrocoll. 25:958-967. 